\title{
Resveratrol prevents angiotensin II-induced hypertrophy of vascular smooth muscle cells through the transactivation of growth factor receptors
}

\begin{tabular}{|r|l|}
\hline Journal: & Canadian Journal of Physiology and Pharmacology \\
\hline Manuscript ID & cjpp-2017-0164.R1 \\
\hline Manuscript Type: & Article \\
\hline Date Submitted by the Author: & 05-Apr-2017 \\
\hline $\begin{array}{r}\text { Complete List of Authors: } \\
\text { Is the invited manuscript for } \\
\text { consideration in a Special } \\
\text { Issue?: }\end{array}$ & $\begin{array}{l}\text { Hossain, Ekhtear; University of Montreal, Pharmacology and Physiology } \\
\text { Physiology }\end{array}$ \\
\hline Keyword: & Resveratrol, Angiotensin II, Oxidative stress, c-Src, Growth factor receptor \\
\hline &
\end{tabular}


Resveratrol prevents angiotensin II-induced hypertrophy of vascular smooth muscle cells through the transactivation of growth factor receptors

\author{
Ekhtear Hossain and Madhu B. Anand-Srivastava* \\ Department of Pharmacology and Physiology, Faculty of Medicine, University of Montreal, \\ Montreal, Canada.
}

Running title: Resveratrol prevents Ang II-induced VSMC hypertrophy

\author{
*Correspondence address: \\ Madhu B. Anand-Srivastava, Ph. D. \\ Professor \\ Department of Pharmacology and Physiology \\ Faculty of Medicine \\ University of Montreal \\ Pavillon Paul-G. Desmarais \\ C.P. 6128, succursale Centre-ville \\ Montreal, Quebec, Canada \\ H3C 3J7 \\ Tel: (514) 343-2091 \\ Fax: (514) 343-2111 \\ E-mail: madhu.anand-srivastava@umontreal.ca
}




\begin{abstract}
We previously showed that the augmented levels of endogenous angiotensin II (Ang II) contribute to vascular smooth muscle cell (VSMC) hypertrophy through the transactivation of growth factor receptors in spontaneously hypertensive rats. Resveratrol (RV), a polyphenolic component of red wine, has also been shown to attenuate Ang II-evoked VSMC hypertrophy, however, the molecular mechanism mediating this response is obscure. The present study is therefore undertaken to examine if RV could prevent Ang II-induced VSMC hypertrophy through the transactivation of growth factor receptor and associated signaling pathways. Ang II treatment of VSMC enhanced the protein synthesis which was attenuated towards control levels by RV pre-treatment as well as by the inhibitors of NADPH oxidase, c-Src, and growth factor receptors. Furthermore, RV pre-treatment also inhibited the enhanced levels of superoxide anion, NADPH oxidase activity, the increased expression of NADPH oxidase subunits and phosphorylation of c-Src, EGF-R, PDGE-R, ERK1/2, and AKT1/2. In conclusion, these results indicate that RV attenuates Ang II-induced VSMC hypertrophy through the inhibition of enhanced oxidative stress, activation of c-Src, growth factor receptors and MAPK/AKT signaling. It may be suggested that RV could be used as a therapeutic agent in the treatment of vascular complications associated with hypertension and hypertrophy.

Keywords: Resveratrol, Angiotensin II, Oxidative stress, c-Src, Growth factor receptor
\end{abstract}




\section{Introduction}

Hypertrophy and hyperproliferation of vascular smooth muscle cells (VSMCs) contribute to vascular remodeling that is attributed to several vascular diseases such as atherosclerosis, restenosis, and hypertension (Touyz 2005). Angiotensin II (Ang II), the main vasoactive peptide of the renin-angiotensin-aldosterone system (RAAS), regulates a variety of pathophysiological functions including high blood pressure, VSMC hyperproliferation, and hypertrophy (Atef and Anand-Srivastava 2014; Beaucage and Moreau 2004; Bouallegue et al. 2009) by the activation of various signaling mechanisms including adenylyl cyclase/cAMP, phosphatidyl inositide 3kinases (PI3K), mitogen-activated protein kinase (MAPK), and tyrosine kinase pathways (Gomez Sandoval and Anand-Srivastava 2011; Gusan and Anand-Srivastava 2013; Nakashima et al. 2008). At the cellular level, Ang II elicits these molecular signals by interacting with two distinct subtypes of receptor, designated $\mathrm{AT}_{1}$ and $\mathrm{AT}_{2}$ (Timmermans et al. 1993). Both $\mathrm{AT}_{1}$ and $\mathrm{AT}_{2}$ receptors are present in heart muscle as well as in cardiomyocytes and mediate the physiological effects of Ang II (Bkaily et al. 2005; Booz and Baker 1996). In addition, $\mathrm{AT}_{1}$ receptor subtype is also present in rat vascular tissues, however, a small proportion of $\mathrm{AT}_{2}$ receptors are present in rat aorta, (Chang and Lotti 1991). Most of the pathophysiological effects of Ang II are mediated by the activation of $\mathrm{AT}_{1}$ receptors. Ang II has also been shown to increase the oxidative stress due to the production of reactive oxygen species (ROS) through the activation of NADPH oxidase (Griendling et al. 1994; Seshiah et al. 2002). ROS through the activation of various downstream kinases, including MAPK and the serine/threonine kinase AKT (also known as protein kinase B or PKB), are implicated in Ang II-induced hypertrophic response of VSMCs (Ushio-Fukai et al. 1998; Ushio-Fukai et al. 1999). We also reported that enhanced levels of endogenous Ang II in VSMC from spontaneously hypertensive rat (SHR) 
through oxidative stress, transactivation of growth factor receptors; insulin-like growth factor receptor (IGF-R), epidermal growth factor receptor (EGF-R), and platelet-derived growth factor receptor (PDGF-R) and associated MAPK signaling, contributes to VSMC hypertrophy (Atef and Anand-Srivastava 2016a).

Resveratrol (RV), an antioxidant and an important polyphenolic component of red wine has been shown to attenuate the development of hypertension in SHR and other experimental models of hypertensive rats (Bhatt et al. 2011) as well as cardiac hypertrophy (Petrovski et al. 2011). In addition, RV has also been shown to attenuate Ang II-evoked VSMC hypertrophy through the inhibition of AKT/protein kinase B and p70 S6 kinase phosphorylation (Haider et al. 2002). However, whether RV inhibits Ang II-induced VSMC hypertrophy through the attenuation of growth factor receptor transactivation and associated signaling pathways that have been implicated in hypertrophy of VSMC has not been explored. Therefore, the present study was undertaken to investigate the effect of RV on Ang II-induced VSMC hypertrophy and to delineate the role of the transactivation of growth factor receptor and associated signaling in the antihypertrophic effect of RV.

We showed that RV inhibits Ang II-induced VSMC hypertrophy through its ability to attenuate oxidative stress, activation of c-Src, growth factor receptors and MAPK/AKT signalling pathways. 


\section{Materials and Methods}

\section{Materials}

Resveratrol (3,4',5-trihydroxy-trans-stilbene), Angiotensin II (human), epidermal growth factor receptor (EGF-R) inhibitor AG1478, platelet-derived growth factor receptor (PDGF-R) inhibitor AG1295, c-Src inhibitor PP2, inactive analog for Src inhibitor PP3 and inhibitor of NADPH oxidase diphenleneiodonium (DPI) were purchased from Sigma-Aldrich Chemical Co. (St Louis, Missouri, USA). Western blotting primary antibodies against EGF-R (sc-373746), pEGF-R (sc-101668, phosphospecific-tyrosine ${ }^{113}$ ), PDGFR- $\beta$ (sc-432), p-PDGFR- $\beta$ (sc-12909-R, phosphospecific-tyrosine ${ }^{1021}$ ), c-Src (sc-18), p-c-Src (sc-166860, phosphospecific-tyrosine ${ }^{419}$ ), ERK1/2 (sc-135900), p-ERK1/2 (sc-7383, phosphospecific-tyrosine ${ }^{204}$ ), AKT1/2/3 (sc-8312), pAKT1/2/3 (sc-7985-R, phosphospecific-serine ${ }^{47}$ ), Nox-1 (sc-5821), dynein IC1/2 (sc-13524), secondary antibodies goat anti-mouse IgG horseradish-peroxidase (HRP) conjugate (sc-2005), donkey anti-goat IgG horseradish-peroxidase (HRP) conjugate (sc-2020) and enhanced chemiluminescence (ECL) detection system kits were purchased from Santa-Cruz Biotechnologies (Santa Cruz, CA, USA). Anti-p47-phox (07-497) and Nox-4 (ABC271) primary antibodies were purchased from EMD Millipore (USA). Anti-Nox-2/gp91phox (ab129068) primary antibody was purchased from Abcam Inc (ON, Canada). Secondary antibody Goat AntiRabbit IgG (H+L)-HRP conjugate was purchased from BIO RAD (USA). The L- $\left[{ }^{14} \mathrm{C}(\mathrm{U})\right]-$ Leucine was from PerkinElmer Inc. (Waltham, Massachusetts, USA). All other chemicals used in the experiments were purchased from Sigma-Aldrich. 


\section{Methods}

\section{Animal preparation}

Male Sprague Dawley (SD) rats (225 to 230 g, ten-week-old) purchased from Charles River (Saint-Constant, Québec, Canada) were maintained on a standard rat chow diet and tap water ad libitum with a 12:12 h light:dark cycle in a quiet environment for two weeks (acclimatization). The rats were anesthetized by $\mathrm{CO}_{2}$ exposure and then euthanized by decapitation. The aortas were dissected out and used for cell culture as described previously (Anand-Srivastava et al. 1982). All the animal procedures used in the present study were approved by the Comité de Déontologie de l'Expérimentation sur les Animaux (CDEA) of the University of Montreal (Approval no. 99050). The investigation conforms to the "Guide for the Care and Use of Laboratory Animals" published by the US National Institutes of Health (NIH) (Guide, NRC 2011).

\section{Cell culture, incubation, and cell lysis}

Aortic VSMCs from twelve-week-old SD rats were cultured as described previously (Anand-Srivastava et al. 1982). The cell purity was determined by immunofluorescence using $\alpha$ actin as described previously (Liau and Chan 1989). The cells were found to contain high levels of smooth muscle-specific $\alpha$-actin. Cells were plated in $100 \mathrm{~mm}$ culture dishes and incubated at $37^{\circ} \mathrm{C}$ in $95 \%$ air, $5 \% \mathrm{CO}_{2}$, humidified atmosphere in Dulbecco's Modified Eagle's Medium (DMEM, with glucose, L-glutamine, and sodium bicarbonate) containing 1\% antibiotics (containing penicillin, streptomycin, and amphotrecin B) and 10\% heat-inactivated fetal bovine serum (FBS). Cells were passaged upon reaching confluence with $0.5 \%$ trypsin and used between passages two and ten. Subconfluent cell cultures were inactivated by incubation for $12 \mathrm{~h}$ in DMEM without FBS at $37^{\circ} \mathrm{C}$ to reduce the interference by growth factors present in the 
serum. After inactivation, aortic VSMCs were pre-incubated in the absence or presence of different concentrations of $\operatorname{RV}(10,30$ and $50 \mu \mathrm{M})$ or $30 \mu \mathrm{M}$ for $1 \mathrm{~h}$ before stimulation with $10^{-6}$ M Ang II, a concentration previously shown to be effective in VSMC ( $\mathrm{Li}$ and Anand-Srivastava 2012; Li et al. 2007). After $24 \mathrm{~h}$ incubation, the cells were washed twice with ice-cold phosphate buffer saline (PBS) and lysed in a $200 \mu \mathrm{l}$ buffer containing $25 \mathrm{mM}$ Tris-HCl (pH 7.5), $25 \mathrm{mM}$ $\mathrm{NaCl}, 1 \mathrm{mM}$ sodium orthovanadate, $10 \mathrm{mM}$ sodium fluoride, $10 \mathrm{mM}$ sodium pyrophosphate, 2 mM EDTA, $1 \mathrm{mM}$ phenylmethylsulfonyl fluoride, $10 \mu \mathrm{g} / \mathrm{mL}$ aprotinin, $1 \%$ Triton $\mathrm{X}-100,0.1 \%$ sodium dodecyl sulfate, and $0.5 \mu \mathrm{g} / \mathrm{mL}$ leupeptin on ice. The cell lysates were centrifuged at $12000 \mathrm{~g}$ for $15 \mathrm{~min}$ at $4^{\circ} \mathrm{C}$, and the supernatants were used for Western blot analysis. Protein concentrations were measured with a Bradford assay (Bradford 1976).

\section{Western blotting}

The levels of protein expression and phosphorylation were determined by Western blotting as described previously (Atef and Anand-Srivastava 2016a). After SDS-PAGE, the separated proteins were transferred to a nitrocellulose membrane with a semi-dry transblot apparatus (Bio-Rad Laboratories, Mississauga, Ontario, Canada) at $15 \mathrm{~V}$ for 45 min (Nox-1, gp91 $1^{\text {phox }}$, Nox-4, p47 $7^{\text {phox }}, \mathrm{c}-\mathrm{Src}, \mathrm{AKT} 1 / 2$, and ERK1/2) or a liquid transfer apparatus (Bio-Rad Laboratories) at $100 \mathrm{~V}$ for $1 \mathrm{~h}$ (EGF-R, and PDGF-R). After transfer, membranes were blocked for $1 \mathrm{~h}$ at room temperature with 5\% dry milk and incubated overnight with specific antibodies against different proteins. Dynein was used for loading controls. The antibody-antigen complexes were detected by incubating the membranes with HRP-conjugated antibodies for $1 \mathrm{~h}$ at room temperature. The blots were then washed three times with PBS before reaction with enhanced chemiluminescence (ECL). Quantitative analysis of the proteins was performed by densitometric scanning of the autoradiographs using the enhanced laser densitometer LKB 
Ultroscan XL and quantified using the gel-scan XL evaluation software (version 2.1) from Pharmacia (Baie d'Urfé, Québec, Canada).

\section{$\left[{ }^{3} \mathbf{H}\right]$-Leucine incorporation assays}

Cell hypertrophy was quantified by protein biosynthesis. Protein biosynthesis was evaluated by $\left[{ }^{3} \mathrm{H}\right]$-Leucine incorporation into cells as described previously (Atef and AnandSrivastava 2016a). Subconfluent VSMCs from twelve-week-old SD rats were inactivated by incubation for $12 \mathrm{~h}$ in serum-free DMEM at $37^{\circ} \mathrm{C}$. The inactivated VSMCs were pre-incubated in the absence or presence of $30 \mu \mathrm{M}$ or different concentrations of RV (10-50 $\mu \mathrm{M})$, DPI (10 $\mu \mathrm{M})$, AG1478 $(10 \mu \mathrm{M})$, AG1295 $(10 \mu \mathrm{M})$, PP2 $(1 \mu \mathrm{M})$, and PP3 $(1 \mu \mathrm{M})$ for $1 \mathrm{~h}$ before stimulation with or without $10^{-6} \mathrm{M}$ Ang II. These concentrations of different inhibitors/antagonists have been used in earlier studies (Gomez Sandoval and Anand-Srivastava 2011; Ichiki et al. 2004; Li et al. 2010). After $12 \mathrm{~h},\left[{ }^{3} \mathrm{H}\right]$-Leucine $(2 \mu \mathrm{Ci}$ per well) was added and further incubated for $12 \mathrm{~h}$ before cells were harvested. Cells were rinsed twice with ice-cold PBS and incubated with 5\% trichloroacetic acid (TCA) for $1 \mathrm{~h}$ at $4{ }^{\circ} \mathrm{C}$. After being washed twice with ice-cold water, cells were incubated with $0.4 \mathrm{~N}$ sodium hydroxide $(\mathrm{NaOH})$ solution for $30 \mathrm{~min}$ at room temperature, and radioactivity was determined with a liquid scintillation counter and adjusted by protein concentration. Cell viability was checked by the trypan blue exclusion technique and indicated that $>90 \sim 95 \%$ cells were viable.

\section{Protein/DNA ratio measurements}

Cell hypertrophy was also assessed by calculating the ratio of total protein to genomic DNA (gDNA) content as described previously (McKay et al. 1998). For this assessment, VSMCs were plated in six-well plates at a seeding density of 2 to $3 \times 10^{4}$ cells/well. After starvation by incubation in DMEM without FBS at $37^{\circ} \mathrm{C}$ as described above, VSMCs were pre-incubated in 
the absence or presence of different concentrations of RV for $1 \mathrm{~h}$ and subsequently stimulated with or without $10^{-6} \mathrm{M}$ Ang II for $24 \mathrm{~h}$. After stimulation, cells were washed in ice-cold PBS and gDNA extraction from each sample was carried out by using PureLink Genomic DNA Mini Kit (Thermo Fisher Scientific, Waltham, MA, USA) following the manufacturer's instructions. DNA concentration was determined by NanoDrop ND-2000c Spectrophotometer (Thermo Fisher Scientific, Waltham, MA). The total protein content was estimated colorimetrically using the method described by Bradford (Bradford 1976). Serial concentrations of calf thymus DNA and bovine serum albumin (BSA) were used for the calibration curves.

\section{Superoxide anion $\left(\mathrm{O}_{2}^{-}\right)$measurements}

Basal $\mathrm{O}_{2}^{-}$production in VSMCs was measured by the lucigenin-enhanced chemiluminescence method with a low concentration $(5 \mu \mathrm{M} / \mathrm{L})$ of lucigenin as described previously (Atef and Anand-Srivastava 2016b). The VSMCs were pre-incubated in the absence or presence of $\mathrm{RV}(30 \mu \mathrm{M})$ for $1 \mathrm{~h}$ and subsequently stimulated with or without $10^{-6} \mathrm{M}$ of Ang II for $24 \mathrm{~h}$. After treatment with Ang II, VSMCs were washed in oxygenated Krebs-HEPES buffer, scraped, and placed in scintillation vials containing lucigenin solution, and the emitted luminescence was measured with a liquid scintillation counter (Wallac 1409; Perkin Elmer Life Science, St Laurent, QC, Canada) for $5 \mathrm{~min}$. The average luminescence value was estimated and the background value subtracted, and the result was divided by the total weight of proteins in each sample.

\section{NADPH oxidase activity determination}

The activation of NADPH oxidase activity in the samples was assessed by adding $10^{-4}$ $\mathrm{M} / \mathrm{L}$ NADH (Sigma) in the vials before counting. Basal $\mathrm{O}_{2}^{-}$-induced luminescence was then subtracted from the luminescence value induced by NADH (Atef and Anand-Srivastava 2016b). 


\section{Statistical analysis}

Results are expressed as means \pm SE (Standard Error). Comparisons between groups were made with one-way analysis of variance (ANOVA) followed by Bonferroni's post-hoc test using GraphPad Prism version 5 (GraphPad Software Inc., La Jolla, California, USA). A difference between groups was significant at $p<0.05$. 


\section{Results}

\section{RV inhibits Ang II-induced VSMC hypertrophy}

Figure 1 shows the effect of different concentrations of RV on Ang II-induced hypertrophy of aortic VSMC. As reported earlier (Haider et al. 2002), Ang II enhanced the [ $\left.{ }^{3} \mathrm{H}\right]-$ Leucine incorporation (Figure 1A) and protein/DNA ratio (Figure 1B) (markers of cell hypertrophy) in VSMC by about $120 \%$ and $70 \%$ respectively and RV pre-treatment attenuated the hypertrophy in a concentration-dependent manner. At $30 \mu \mathrm{M}, \mathrm{RV}$ attenuated Ang II-induced $\left[{ }^{3} \mathrm{H}\right]$-Leucine incorporation and protein/DNA ratio to almost control level whereas at $50 \mu \mathrm{M} \mathrm{RV}$, the Ang II-induced $\left[{ }^{3} \mathrm{H}\right]$-Leucine incorporation was inhibited below control levels. In addition, $\mathrm{RV}$ at 30 and $50 \mu \mathrm{M}$ also reduced the $\left[{ }^{3} \mathrm{H}\right]$-Leucine incorporation and protein/DNA ratio by approximately 20 to $30 \%$ in control cells (Figure 1A). Therefore, $30 \mu \mathrm{M}$ RV was used for further studies.

\section{RV inhibits Ang II-induced oxidative stress}

Ang II has been shown to stimulate NADPH oxidases and produce reactive oxygen species (ROS) resulting in increased oxidative stress (Seshiah et al. 2002). To investigate if Ang II-induced enhanced protein synthesis in VSMC is due to enhanced oxidative stress, the effect of DPI, an inhibitor of NADPH oxidase on protein synthesis was examined. As shown in Figure 2A, the protein synthesis in VSMC that was significantly augmented by Ang II treatment by about $70 \%$ was completely attenuated to control level by DPI pre-treatment. In addition, DPI also inhibited the protein synthesis in control cells by about $50 \%$. To further examine if RVinhibits Ang II-induced hypertrophy through its ability to attenuate the enhanced oxidative stress, the effect of RV on the Ang II-mediated production of superoxide anion $\left(\mathrm{O}_{2}^{-}\right)$and NADPH oxidase activity was examined. As reported earlier (Li et al. 2007), Ang II enhanced the 
production of $\mathrm{O}_{2}^{-}$(Figure 2B) and NADPH oxidase activity (Figure 2C) in VSMCs by about $100 \%$ and $75 \%$ respectively and RV pre-treatment attenuated completely the enhanced levels of $\mathrm{O}_{2}{ }^{-}$and NADPH oxidase activity to control levels. In addition, RV treatment decreased the basal levels of $\mathrm{O}_{2}^{-}$and NADPH oxidase activity by about $25 \%$ and $40 \%$ respectively in control cells.

To further investigate if the inhibition of enhanced activity of NADPH oxidase induced by Ang II by RV is attributed to its ability to decrease the expression of different subunits of NADPH oxidase, the effect of RV pre-treatment on Ang II-stimulated enhanced expression of Nox-1, gp91 ${ }^{\text {phox }}$, Nox-4, and p4 $7^{\text {phox }}$ were examined in VSMC. As shown in Figure 3A-D, Ang II treatment significantly enhanced the levels of Nox-1, gp91 ${ }^{\text {phox }}$, Nox-4, and $\mathrm{p} 47^{\text {phox }}$ subunits by about $80 \%, 40 \%, 60 \%$ and $130 \%$ respectively which were almost completely attenuated by RV pre-treatment. On the other hand, the expression of Nox-1, gp9 $1^{\text {phox }}$, Nox-4, and $47^{\text {phox }}$ subunits were not altered by RV treatment alone.

\section{RV inhibits Ang II-induced c-Src activation}

We previously showed the implication of c-Src activation in oxidative stress-induced enhanced protein synthesis in VSMCs from SHRs (Atef and Anand-Srivastava 2014). To investigate the implication of c-Src in Ang II-induced VSMC hypertrophy, the effect of PP2, a specific inhibitor of c-Src on Ang II-induced protein synthesis in VSMC was examined. Results shown in Figure 4A indicate that the enhanced protein synthesis induced by Ang II was attenuated to control levels by PP2. In addition, PP2 also decreased the protein synthesis by about $65 \%$ in control cells. Furthermore, treatment of VSMCs with PP3, an inactive structural analog of PP2, did not have any significant effect on Ang II-enhanced protein synthesis (data not shown). 
To further investigate if RV- induced attenuation of Ang II-stimulated protein synthesis is also attributed to its ability to inhibit the enhanced activation of c-Src, the effect of RV on Ang II-induced c-Src phosphorylation in VSMC was examined. Results shown in Figure 4B indicate that Ang II significantly augmented by about $70 \%$, the phosphorylation of $\mathrm{Tyr}^{418}$ on c-Src in VSMC as compared to control cells and RV pre-treatment completely attenuated the enhanced phosphorylation of c-Src to control level. On the other hand, the expression of total c-Src was not altered by these treatments.

\section{RV inhibits Ang II-induced growth factor receptor activation}

Ang II-stimulated transactivation of EGF-R was shown to play a crucial role in cardiovascular remodeling including cardiac hypertrophy (Peng et al. 2016). We have shown recently that augmented levels of endogenous Ang II through the transactivation of growth factor receptors EGF-R and PDGF-R contribute to VSMC hypertrophy in SHR (Atef and AnandSrivastava 2014). Therefore, it was also important to examine the role of EGF-R and PDGF-R in Ang II-induced VSMC hypertrophy. To test these, the effects of AG1478, a specific inhibitor of EGF-R and AG1295, a specific inhibitor of PDGF-R on Ang II-induced enhanced protein synthesis were examined in VSMC. Figure $5 \mathrm{~A}$ shows that Ang II-induced enhanced $(\approx 60 \%)$ protein synthesis was completely attenuated to control levels by AG1478 and AG1295. In addition, both these inhibitors also inhibited protein synthesis in control cells by about 40-50\%.

To gain insight into whether RV attenuates Ang II-mediated hypertrophy via inhibition of transactivation of EGF-R and PDGF-R in VSMC, we examined the effect of RV pre-treatment on Ang II-induced phosphorylation of EGF-R and PDGF-R in VSMC. Results shown in Figure 5B and $\mathrm{C}$ indicate that Ang II enhanced the phosphorylation of EGF-R and PDGF-R by about $200 \%$ and $70 \%$ respectively which were almost completely attenuated to control levels by RV 
pre-treatment. In addition, RV also decreased the phosphorylation of EGF-R and PDGF-R by about $35 \%$ and $65 \%$ respectively in control cells. On the other hand, the expressions of total EGF-R and PDGF-R was not altered by these treatments.

\section{RV inhibits Ang II-induced ERK1/2 and AKT/PKB activation}

Growth factor receptors (GFRs) have been shown to signal through MAPK and AKT pathways (Oda et al. 2005). Since RV inhibits Ang II-induced activation of growth factor receptors, it was of interest to examine the effect of RV pre-treatment on Ang II-stimulated ERK1/2 and AKT1/2 activation. As reported earlier (Haider et al. 2002; Zhang et al. 2012), Ang II significantly enhanced the phosphorylation of ERK1/2 (Figure 6A) and AKT1/2 (Figure 6B) by about $100 \%$ and $200 \%$ respectively and RV pre-treatment completely attenuated the Ang IIinduced enhanced activation of ERK1/2 as well as of AKT1/2. In addition, RV treatment also decreased the basal phosphorylation level of ERK1/2 and not of AKT1/2 by about $40 \%$ in control cells. 


\section{Discussion}

The present study provides insight into the molecular mechanisms through which RV attenuates Ang II-induced hypertrophy of VSMC. Although, the inhibition of Ang II-induced $\mathrm{AKT} /$ protein kinase $\mathrm{B}(\mathrm{PKB})$ and p70 S6 kinase phosphorylation by $\mathrm{RV}$, and the subsequent attenuation of hypertrophy of rat aortic VSMC has been shown earlier (Haider et al. 2002), we show for the first time that RV attenuates Ang II-stimulated VSMC hypertrophy through the inhibition of c-Src and growth factor receptor activation, the upstream signaling molecules of AKT pathway.

Growth factor receptor transactivation by G protein coupled receptor (GPCR) including $\mathrm{AT}_{1}$ receptor is well established (Daub et al. 1996; Gomez Sandoval et al. 2009; Itoh et al. 1993). In addition, the enhanced activation of growth factor receptors EGF-R and PDGF-R exhibited by VSMC from SHR was also shown to be attributed to the enhanced levels of endogenous Ang II (Atef and Anand-Srivastava 2016a; Li et al. 2010; Sandoval et al. 2011). Furthermore, the implication of EGF-R transactivation induced by endogenous Ang II has been shown to mediate VSMC hypertrophy in SHR (Atef and Anand-Srivastava 2014). Consistent with results reported by others (Beaucage and Moreau 2004; Bokemeyer et al. 2000; Eguchi et al. 1998; Gao et al. 2006), we also show that Ang II enhanced the phosphorylation (activation) of both EGF-R and PDGF-R in VSMC and the activation of both EGF-R and PDGF-R contributes to Ang II-induced VSMC hypertrophy because the inhibition of EGF-R and PDGF-R by inhibitors AG1478 and AG1295 attenuated the hypertrophy of VSMC. Furthermore, the fact that pre-treatment of VSMC with RV inhibited Ang II-induced activation of EGF-R and PDGF-R strongly suggests that RV inhibits Ang II-evoked VSMC hypertrophy through the inhibition of growth factor receptor activation. Our results are in contrast with the studies of Haider et al. (Haider et al. 
2005) who did not observe the inhibitory effect of RV on Ang II-induced enhanced phosphorylation of EGF-R in VSMC. The observed discrepancy may be attributed to the different experimental conditions used (30 $\mu \mathrm{M}$ RV vs $100 \mu \mathrm{M} \mathrm{RV})$.

Our results showing that Ang II augments the production of $\mathrm{O}_{2}^{-}$, NADPH oxidase activity and expression of Nox-1, gp9 $1^{\text {phox }}$, Nox-4, and $\mathrm{p} 47^{\text {phox }}$ in VSMC are consistent with the studies reported earlier (Lassegue et al. 2001; Li et al. 2010; Touyz et al. 2002; Wingler et al. 2001). A role of oxidative stress in VSMC hypertrophy in SHR has been reported (Atef and AnandSrivastava 2014, 2016a, b). Furthermore, the fact that DPI attenuates Ang II-induced VSMC hypertrophy further suggests the contribution of oxidative stress in Ang II-induced VSMC hypertrophy. In addition, our results showing that RV inhibits the Ang II-induced enhanced production of $\mathrm{O}_{2}{ }^{-}$, NADPH oxidase activity and enhanced expression of different subunits of NADPH oxidase together with the fact that it inhibits VSMC hypertrophy suggests that RVinduced inhibition of Ang II-stimulated VSMC hypertrophy is attributed to its ability to inhibit oxidative stress. In this regard, the inhibition of vascular NADPH oxidase by RV has been shown (Orallo et al. 2002). In addition, RV has also been shown to markedly suppress the increased activity of NADPH oxidase, as well as the enhanced expressions of gp $91^{\text {phox }}, \mathrm{p} 47^{\text {phox }}$, and Nox-4 induced by high glucose in cardiomyocytes (Guo et al. 2015).

c-Src, a downstream molecule of oxidative stress, through the activation of growth factor receptors has been shown to contribute to VSMC hypertrophy in SHR (Atef and AnandSrivastava 2016a). Our results showing that PP2, an inhibitor of c-Src attenuates Ang IIstimulated VSMC hypertrophy suggests the implication of c-Src in Ang II-induced hypertrophy of VSMC. In addition, the fact that RV inhibits Ang II-induced enhanced phosphorylation of cSrc strongly supports that RV attenuates Ang II-evoked VSMC hypertrophy through the 
inhibition of c-Src activation. In this regard, RV has also been shown to inhibit c-Src tyrosine kinase in Hela cells (Yu et al. 2001).

RV has been reported to suppress Ang II-induced AKT/protein kinase B and subsequent hypertrophy in rat aortic VSMCs (Haider et al. 2002). We also report that RV inhibits the enhanced phosphorylation of ERK1/2 and AKT1/2 induced by Ang II in VSMC. Ang II-induced activation of MAPK/ERK as well as AKT/PKB has been shown to mediate VSMC hypertrophy (Eguchi et al. 1998). In addition, the role of these kinases in hypertrophy of VSMC from SHR has also been shown (Atef and Anand-Srivastava 2014; Servant et al. 1996).We earlier showed that enhanced levels of endogenous Ang II in VSMC from SHR increase oxidative stress which through c-Src and growth factor receptor activation enhance MAPK and AKT activities and result in VSMC hypertrophy (Atef and Anand-Srivastava 2016a). Taken together, it may be suggested that RV attenuates Ang II-induced VSMC hypertrophy through the inhibition of oxidative stress, c-Src, growth factor receptor activation and associated MAPK and AKT signaling pathways.

In conclusion, we provide evidence that RV-induced inhibition of c-Src and growth factor receptor activation may be the important signaling pathways through which it exhibits antihypertrophic effect. It may be suggested that RV could be used as a therapeutic agent in the treatment of vascular complications associated with hypertension and hypertrophy. 


\section{Acknowledgement}

This study was supported by a grant from the Canadian Institutes of Health Research (MOP 53074). We also thank to Drs. Yuan Li and Sara Almajdoob for their valuable laboratory assistance.

\section{Conflicts of interest}

There is no conflict of interest associated with this work. 


\section{References}

Anand-Srivastava, M.B., Franks, D.J., Cantin, M., and Genest, J. 1982. Presence of "Ra" and "P"-site receptors for adenosine coupled to adenylate cyclase in cultured vascular smooth muscle cells. Biochem. Biophys. Res. Commun. 108(1): 213-219. Available from https://www.ncbi.nlm.nih.gov/pubmed/6293481.

Atef, M.E., and Anand-Srivastava, M.B. 2014. Enhanced expression of Gqalpha and PLC-beta1 proteins contributes to vascular smooth muscle cell hypertrophy in SHR: role of endogenous angiotensin II and endothelin-1. Am. J. Physiol. Cell Physiol. 307(1): C97-106. doi: 10.1152/ajpcell.00337.2013.

Atef, M.E., and Anand-Srivastava, M.B. 2016a. Oxidative stress contributes to the enhanced expression of Gqalpha/PLCbeta1 proteins and hypertrophy of VSMC from SHR: role of growth factor receptor transactivation. Am. J. Physiol. Heart Circ. Physiol. 310(5): H608-618. doi: 10.1152/ajpheart.00659.2015.

Atef, M.E., and Anand-Srivastava, M.B. 2016b. Role of PKCdelta in Enhanced Expression of Gqalpha/PLCbeta1 Proteins and VSMC Hypertrophy in Spontaneously Hypertensive Rats. PLoS One, 11(7): e0157955. doi: 10.1371/journal.pone.0157955.

Beaucage, P., and Moreau, P. 2004. EGF receptor transactivation in angiotensin II and endothelin control of vascular protein synthesis in vivo. J. Cardiovasc. Pharmacol. 44 (Suppl. 1): S20-23. Available from https://www.ncbi.nlm.nih.gov/pubmed/15838279.

Bhatt, S.R., Lokhandwala, M.F., and Banday, A.A. 2011. Resveratrol prevents endothelial nitric oxide synthase uncoupling and attenuates development of hypertension in spontaneously hypertensive rats. Eur. J. Pharmacol. doi: S0014-2999(11)00594-2 [pii] 10.1016/j.ejphar.2011.05.026.

Bkaily, G., El-Bizri, N., Nader, M., Hazzouri, K.M., Riopel, J., Jacques, D., et al. 2005. Angiotensin II induced increase in frequency of cytosolic and nuclear calcium waves of heart cells via activation of AT1 and AT2 receptors. Peptides, 26(8): 1418-1426. doi: 10.1016/j.peptides.2005.03.051.

Bokemeyer, D., Schmitz, U., and Kramer, H.J. 2000. Angiotensin II-induced growth of vascular smooth muscle cells requires an Src-dependent activation of the epidermal growth factor receptor. Kidney Int. 58(2): 549-558. doi: 10.1046/j.1523-1755.2000.t01-1-00201.x.

Booz, G.W., and Baker, K.M. 1996. Role of type 1 and type 2 angiotensin receptors in angiotensin II-induced cardiomyocyte hypertrophy. Hypertension, 28(4): 635-640. Available from https://www.ncbi.nlm.nih.gov/pubmed/8843890. 
Bouallegue, A., Vardatsikos, G., and Srivastava, A.K. 2009. Role of insulin-like growth factor 1 receptor and c-Src in endothelin-1- and angiotensin II-induced PKB phosphorylation, and hypertrophic and proliferative responses in vascular smooth muscle cells. Can. J. Physiol. Pharmacol. 87(12): 1009-1018. doi: 10.1139/Y09-056.

Bradford, M.M. 1976. A rapid and sensitive method for the quantitation of microgram quantities of protein utilizing the principle of protein-dye binding. Anal. Biochem. 72: 248-254. Available from https://www.ncbi.nlm.nih.gov/pubmed/942051.

Chang, R.S., and Lotti, V.J. 1991. Angiotensin receptor subtypes in rat, rabbit and monkey tissues: relative distribution and species dependency. Life Sci. 49(20): 1485-1490. Available from https://www.ncbi.nlm.nih.gov/pubmed/1943452.

Daub, H., Weiss, F.U., Wallasch, C., and Ullrich, A. 1996. Role of transactivation of the EGF receptor in signalling by G-protein-coupled receptors. Nature, 379(6565): 557-560. doi: $10.1038 / 379557 \mathrm{a} 0$.

Eguchi, S., Numaguchi, K., Iwasaki, H., Matsumoto, T., Yamakawa, T., Utsunomiya, H., et al. 1998. Calcium-dependent epidermal growth factor receptor transactivation mediates the angiotensin II-induced mitogen-activated protein kinase activation in vascular smooth muscle cells. J. Biol. Chem. 273(15): 8890-8896. Available from https://www.ncbi.nlm.nih.gov/pubmed/9535870.

Gao, B.B., Hansen, H., Chen, H.C., and Feener, E.P. 2006. Angiotensin II stimulates phosphorylation of an ectodomain-truncated platelet-derived growth factor receptor-beta and its binding to class IA PI3K in vascular smooth muscle cells. Biochem. J. 397(2): 337-344. doi: 10.1042/BJ20060095.

Gomez Sandoval, Y.H., and Anand-Srivastava, M.B. 2011. Enhanced levels of endogenous endothelin-1 contribute to the over expression of Gialpha protein in vascular smooth muscle cells from SHR: Role of growth factor receptor activation. Cell. Signal. 23(2): 354-362. doi: 10.1016/j.cellsig.2010.10.005.

Gomez Sandoval, Y.H., Levesque, L.O., and Anand-Srivastava, M.B. 2009. Contribution of epidermal growth factor receptor transactivation in angiotensin II-induced enhanced expression of Gi protein and proliferation in A10 vascular smooth muscle cells. Can. J. Physiol. Pharmacol. 87(12): 1037-1045. doi: 10.1139/Y09-089.

Griendling, K.K., Minieri, C.A., Ollerenshaw, J.D., and Alexander, R.W. 1994. Angiotensin II stimulates NADH and NADPH oxidase activity in cultured vascular smooth muscle cells. Circ. Res. 74(6): 1141-1148. Available from https://www.ncbi.nlm.nih.gov/pubmed/8187280.

Guo, S., Yao, Q., Ke, Z., Chen, H., Wu, J., and Liu, C. 2015. Resveratrol attenuates high glucose-induced oxidative stress and cardiomyocyte apoptosis through AMPK. Mol. Cell. Endocrinol. 412: 85-94. doi: 10.1016/j.mce.2015.05.034. 
Gusan, S., and Anand-Srivastava, M.B. 2013. cAMP attenuates the enhanced expression of Gi proteins and hyperproliferation of vascular smooth muscle cells from SHR: role of ROS and ROS-mediated signaling. Am. J. Physiol. Cell Physiol. 304(12): C1198-1209. doi: 10.1152/ajpcell.00269.2012.

Haider, U.G., Roos, T.U., Kontaridis, M.I., Neel, B.G., Sorescu, D., Griendling, K.K., et al. 2005. Resveratrol inhibits angiotensin II- and epidermal growth factor-mediated Akt activation: role of Gab1 and Shp2. Mol. Pharmacol. 68(1): 41-48. doi: 10.1124/mol.104.005421.

Haider, U.G., Sorescu, D., Griendling, K.K., Vollmar, A.M., and Dirsch, V.M. 2002. Resveratrol suppresses angiotensin II-induced Akt/protein kinase B and p70 S6 kinase phosphorylation and subsequent hypertrophy in rat aortic smooth muscle cells. Mol. Pharmacol. 62(4): 772-777. Available from https://www.ncbi.nlm.nih.gov/pubmed/12237323.

Ichiki, T., Tokunou, T., Fukuyama, K., Iino, N., Masuda, S., and Takeshita, A. 2004. 15-DeoxyDelta12,14-prostaglandin $\mathrm{J} 2$ and thiazolidinediones transactivate epidermal growth factor and platelet-derived growth factor receptors in vascular smooth muscle cells. Biochem. Biophys. Res. Commun. 323(2): 402-408. doi: 10.1016/j.bbrc.2004.08.101.

Itoh, H., Mukoyama, M., Pratt, R.E., Gibbons, G.H., and Dzau, V.J. 1993. Multiple autocrine growth factors modulate vascular smooth muscle cell growth response to angiotensin II. J. Clin. Invest. 91(5): 2268-2274. doi: 10.1172/JCI116454.

Lassegue, B., Sorescu, D., Szocs, K., Yin, Q., Akers, M., Zhang, Y., et al. 2001. Novel gp91(phox) homologues in vascular smooth muscle cells : nox 1 mediates angiotensin II-induced superoxide formation and redox-sensitive signaling pathways. Circ. Res. 88(9): 888-894. Available from https://www.ncbi.nlm.nih.gov/pubmed/11348997.

Li, Y., and Anand-Srivastava, M.B. 2012. Implication of multiple signaling pathways in the regulation of angiotensin II induced enhanced expression of Gialpha proteins in vascular smooth muscle cells. Can. J. Physiol. Pharmacol. 90(8): 1105-1116. doi: 10.1139/y2012-042.

Li, Y., Lappas, G., and Anand-Srivastava, M.B. 2007. Role of oxidative stress in angiotensin IIinduced enhanced expression of Gi(alpha) proteins and adenylyl cyclase signaling in A10 vascular smooth muscle cells. Am. J. Physiol. Heart Circ. Physiol. 292(4): H1922-1930. doi: 10.1152/ajpheart.01166.2006.

Li, Y., Levesque, L.O., and Anand-Srivastava, M.B. 2010. Epidermal growth factor receptor transactivation by endogenous vasoactive peptides contributes to hyperproliferation of vascular smooth muscle cells of SHR. Am. J. Physiol. Heart Circ. Physiol. 299(6): H1959-1967. doi: 10.1152/ajpheart.00526.2010.

Liau, G., and Chan, L.M. 1989. Regulation of extracellular matrix RNA levels in cultured smooth muscle cells. Relationship to cellular quiescence. J. Biol. Chem. 264(17): 10315-10320. Available from https://www.ncbi.nlm.nih.gov/pubmed/2470763. 
McKay, S., de Jongste, J.C., Saxena, P.R., and Sharma, H.S. 1998. Angiotensin II induces hypertrophy of human airway smooth muscle cells: expression of transcription factors and transforming growth factor-beta1. Am. J. Respir. Cell Mol. Biol. 18(6): 823-833. doi: 10.1165/ajrcmb.18.6.2924.

Nakashima, H., Frank, G.D., Shirai, H., Hinoki, A., Higuchi, S., Ohtsu, H., et al. 2008. Novel role of protein kinase C-delta Tyr 311 phosphorylation in vascular smooth muscle cell hypertrophy by angiotensin II. Hypertension, 51(2): 232-238. doi: 10.1161/HYPERTENSIONAHA.107.101253.

Oda, K., Matsuoka, Y., Funahashi, A., and Kitano, H. 2005. A comprehensive pathway map of epidermal growth factor receptor signaling. Mol. Syst. Biol. 1: 2005 0010. doi: $10.1038 / \mathrm{msb} 4100014$.

Orallo, F., Alvarez, E., Camina, M., Leiro, J.M., Gomez, E., and Fernandez, P. 2002. The possible implication of trans-Resveratrol in the cardioprotective effects of long-term moderate wine consumption. Mol. Pharmacol. 61(2): 294-302. Available from https://www.ncbi.nlm.nih.gov/pubmed/11809853.

Peng, K., Tian, X., Qian, Y., Skibba, M., Zou, C., Liu, Z., et al. 2016. Novel EGFR inhibitors attenuate cardiac hypertrophy induced by angiotensin II. J. Cell. Mol. Med. 20(3): 482-494. doi: $10.1111 / \mathrm{jcmm} .12763$.

Petrovski, G., Gurusamy, N., and Das, D.K. 2011. Resveratrol in cardiovascular health and disease. Ann. N. Y. Acad. Sci. 1215: 22-33. doi: 10.1111/j.1749-6632.2010.05843.x.

Sandoval, Y.H., Li, Y., and Anand-Srivastava, M.B. 2011. Transactivation of epidermal growth factor receptor by enhanced levels of endogenous angiotensin II contributes to the overexpression of Gialpha proteins in vascular smooth muscle cells from SHR. Cell. Signal. 23(11): 1716-1726. doi: 10.1016/j.cellsig.2011.06.006.

Servant, M.J., Giasson, E., and Meloche, S. 1996. Inhibition of growth factor-induced protein synthesis by a selective MEK inhibitor in aortic smooth muscle cells. J. Biol. Chem. 271(27): 16047-16052. Available from https://www.ncbi.nlm.nih.gov/pubmed/8663242.

Seshiah, P.N., Weber, D.S., Rocic, P., Valppu, L., Taniyama, Y., and Griendling, K.K. 2002. Angiotensin II stimulation of $\mathrm{NAD}(\mathrm{P}) \mathrm{H}$ oxidase activity: upstream mediators. Circ. Res. 91(5): 406-413. Available from https://www.ncbi.nlm.nih.gov/pubmed/12215489.

Timmermans, P.B., Wong, P.C., Chiu, A.T., Herblin, W.F., Benfield, P., Carini, D.J., et al. 1993. Angiotensin II receptors and angiotensin II receptor antagonists. Pharmacol. Rev. 45(2): 205251. Available from https://www.ncbi.nlm.nih.gov/pubmed/8372104.

Touyz, R.M. 2005. Intracellular mechanisms involved in vascular remodelling of resistance arteries in hypertension: role of angiotensin II. Exp. Physiol. 90(4): 449-455. doi: 10.1113/expphysiol.2005.030080. 
Touyz, R.M., Chen, X., Tabet, F., Yao, G., He, G., Quinn, M.T., et al. 2002. Expression of a functionally active gp91phox-containing neutrophil-type $\mathrm{NAD}(\mathrm{P}) \mathrm{H}$ oxidase in smooth muscle cells from human resistance arteries: regulation by angiotensin II. Circ. Res. 90(11): 1205-1213. Available from https://www.ncbi.nlm.nih.gov/pubmed/12065324.

Ushio-Fukai, M., Alexander, R.W., Akers, M., and Griendling, K.K. 1998. p38 Mitogenactivated protein kinase is a critical component of the redox-sensitive signaling pathways activated by angiotensin II. Role in vascular smooth muscle cell hypertrophy. J. Biol. Chem. 273(24): 15022-15029. Available from https://www.ncbi.nlm.nih.gov/pubmed/9614110.

Ushio-Fukai, M., Alexander, R.W., Akers, M., Yin, Q., Fujio, Y., Walsh, K., et al. 1999. Reactive oxygen species mediate the activation of Akt/protein kinase B by angiotensin II in vascular smooth muscle cells. J. Biol. Chem. 274(32): 22699-22704. Available from https://www.ncbi.nlm.nih.gov/pubmed/10428852.

Wingler, K., Wunsch, S., Kreutz, R., Rothermund, L., Paul, M., and Schmidt, H.H. 2001. Upregulation of the vascular NAD(P)H-oxidase isoforms Nox1 and Nox4 by the reninangiotensin system in vitro and in vivo. Free Radic. Biol. Med. 31(11): 1456-1464. Available from https://www.ncbi.nlm.nih.gov/pubmed/11728818.

Yu, R., Hebbar, V., Kim, D.W., Mandlekar, S., Pezzuto, J.M., and Kong, A.N. 2001. Resveratrol inhibits phorbol ester and UV-induced activator protein 1 activation by interfering with mitogenactivated protein kinase pathways. Mol. Pharmacol. 60(1): 217-224. Available from https://www.ncbi.nlm.nih.gov/pubmed/11408617.

Zhang, X., Wang, Y., Yang, W., Hou, X., Zou, J., and Cao, K. 2012. Resveratrol inhibits angiotensin II-induced ERK1/2 activation by downregulating quinone reductase 2 in rat vascular smooth muscle cells. J. Biomed. Res. 26(2): 103-109. doi: 10.1016/S1674-8301(12)60019-0. 


\section{Figure legends}

Figure 1. Dose-dependent effects of RV on Ang II-induced enhanced $\left[{ }^{3} \mathrm{H}\right]$-Leucine incorporation and protein/DNA ratio in aortic vascular smooth muscle cells (VSMCs). Subconfluent VSMCs were pre-incubated in the absence or presence of different concentration (10 to $50 \mu \mathrm{M})$ of RV for $1 \mathrm{~h}$ and subsequently stimulated with or without Ang II $\left(10^{-6} \mathrm{M}\right)$ for 24 h. After $24 \mathrm{~h},\left[{ }^{3} \mathrm{H}\right]$-Leucine incorporation (Figure A), and protein/DNA ratio (Figure B) were determined as described in the Methods section. Data are expressed as \% of the control group (CTL, taken as $100 \%$ ). Values are the mean \pm SE of three separate independent experiments performed in triplicate. ${ }^{*} p<0.01,{ }^{* *} p<0.001,{ }^{* * *} p<0.0001$ vs. the control (CTL) group, ${ }^{\dagger \dagger} p<$ $0.001,{ }^{\dagger \dagger} p<0.001$ vs. Ang II group.

Figure 2. Effects of RV and DPI on Ang II-induced enhanced oxidative stress and protein synthesis in aortic vascular smooth muscle cells (VSMCs). Subconfluent VSMCs were preincubated in the absence or presence of RV $(30 \mu \mathrm{M})$ or DPI $(10 \mu \mathrm{M})$ for $1 \mathrm{~h}$ and subsequently stimulated with or without Ang II $\left(10^{-6} \mathrm{M}\right)$ for $24 \mathrm{~h}$. After $24 \mathrm{~h},\left[{ }^{3} \mathrm{H}\right]$-Leucine incorporation (Figure 2A), superoxide anion $\left(\mathrm{O}_{2}^{-}\right)$(Figure 2B), and NADPH oxidase activity (Figure 2C) were determined as described in the Methods section. Data are expressed as $\%$ of the control group (CTL, taken as $100 \%$ ). Values are the mean \pm SE of three separate and independent experiments performed in triplicate. ${ }^{*} p<0.01,{ }^{*} p<0.001, * * * p<0.0001$ vs. control (CTL) group; ${ }^{\dagger \dagger} p<$ 0.0001 vs. Ang II group.

Figure 3. Effects of RV on Ang II-induced enhanced expression of NADPH oxidase subunits in aortic vascular smooth muscle cells (VSMCs). Subconfluent VSMCs were preincubated in the absence or presence of $\mathrm{RV}(30 \mu \mathrm{M})$ for $1 \mathrm{~h}$ and subsequently stimulated with or without Ang II $\left(10^{-6} \mathrm{M}\right)$ for $24 \mathrm{~h}$. After $24 \mathrm{~h}$, Nox-1 (Figure 3A), gp91 ${ }^{\text {phox }}$ (Figure 3B), Nox-4 
(Figure 3C), and $\mathrm{p} 47^{\text {phox }}$ (Figure 3D) protein expression levels were determined by Western blot as described in the Methods section. In each subfigure (3A-D), the upper panel is a Western blot image. Data are expressed as \% of the control group (CTL, taken as 100\%). Values are the mean \pm SE of three separate and independent experiments performed in triplicate. ${ }^{*} p<0.01,{ }^{* * *} p<$ 0.0001 vs. control (CTL) group; ${ }^{\dagger} p<0.01,{ }^{\dagger} p<0.001$, vs. Ang II group.

Figure 4. Effects of RV and PP2 on Ang II-induced enhanced phosphorylation of c-Src and protein synthesis in aortic vascular smooth muscle cells (VSMCs). Subconfluent VSMCs were pre-incubated in the absence or presence of RV $(30 \mu \mathrm{M})$ or PP2 $(1 \mu \mathrm{M})$ for $1 \mathrm{~h}$ and subsequently stimulated with or without Ang II $\left(10^{-6} \mathrm{M}\right)$ for $24 \mathrm{~h}$. After $24 \mathrm{~h},\left[{ }^{3} \mathrm{H}\right]$-Leucine incorporation (Figure 4A), and c-Src phosphorylation (Figure 4B) were determined as described in the Methods section. In Figure 4B, the upper panels are Western blot images. Data are expressed as $\%$ of the control group (CTL, taken as 100\%). Values are the mean \pm SE of three separate and independent experiments performed in triplicate. $* * p<0.001, * * * p<0.0001$ vs. control (CTL) group; ${ }^{\dagger \dagger} p<0.001,{ }^{\dagger \dagger \dagger} p<0.0001$ vs. Ang II group.

Figure 5. Effects of RV, AG1478, and AG1295 on Ang II-induced enhanced phosphorylation of EGF-R and PDGF-R and protein synthesis in aortic vascular smooth muscle cells (VSMCs). Subconfluent VSMCs were pre-incubated in the absence or presence of RV $(30 \mu \mathrm{M}), \mathrm{AG} 1478(10 \mu \mathrm{M})$, and AG1295 $(10 \mu \mathrm{M})$ for $1 \mathrm{~h}$ and subsequently stimulated with or without Ang II $\left(10^{-6} \mathrm{M}\right)$ for $24 \mathrm{~h}$. After $\left.24 \mathrm{~h},{ }^{3} \mathrm{H}\right]$-Leucine incorporation (Figure 5A), EGF-R phosphorylation (Figure 5B), and PDGF-R phosphorylation (Figure 5C) were determined as described in the Methods section. In Figure 5B and Figure 5C, the upper panels are Western blot images. Data are expressed as \% of the control group (CTL, taken as 100\%). Values are the 
mean \pm SE of three separate and independent experiments performed in triplicate. $* * p<0.001$ $* * * p<0.0001$ vs. control (CTL) group; ${ }^{\dagger \dagger} p<0.001,{ }^{\dagger \dagger} p<0.0001$ vs. Ang II group.

Figure 6. Effects of RV on Ang II-induced enhanced phosphorylation of ERK1/2 and AKT1/2 in aortic vascular smooth muscle cells (VSMCs). Subconfluent VSMCs were preincubated in the absence or presence of $\mathrm{RV}(30 \mu \mathrm{M})$ for $1 \mathrm{~h}$ and subsequently stimulated with or without Ang II $\left(10^{-6} \mathrm{M}\right)$ for $24 \mathrm{~h}$. After $24 \mathrm{~h}$, ERK1/2 phosphorylation (Figure 6A), and AKT1/2 phosphorylation (Figure 6B) were determined as described in the Methods section. In Figure 6A and Figure 6B, the upper panels are Western blot images. Data are expressed as $\%$ of the control group (CTL, taken as 100\%). Values are the mean \pm SE of three separate and independent experiments performed in triplicate. ${ }^{*} p<0.01,{ }^{* * *} p<0.0001$ vs. control (CTL) group; ${ }^{\dagger} p<$ 0.001 vs. Ang II group. 
$\mathbf{A}$



$\mathbf{B}$

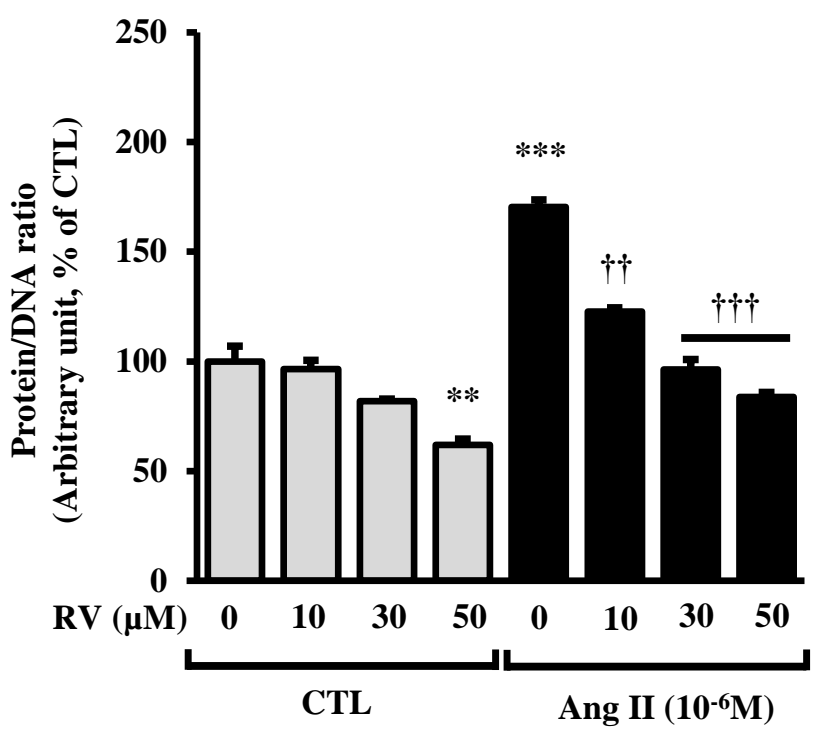


A
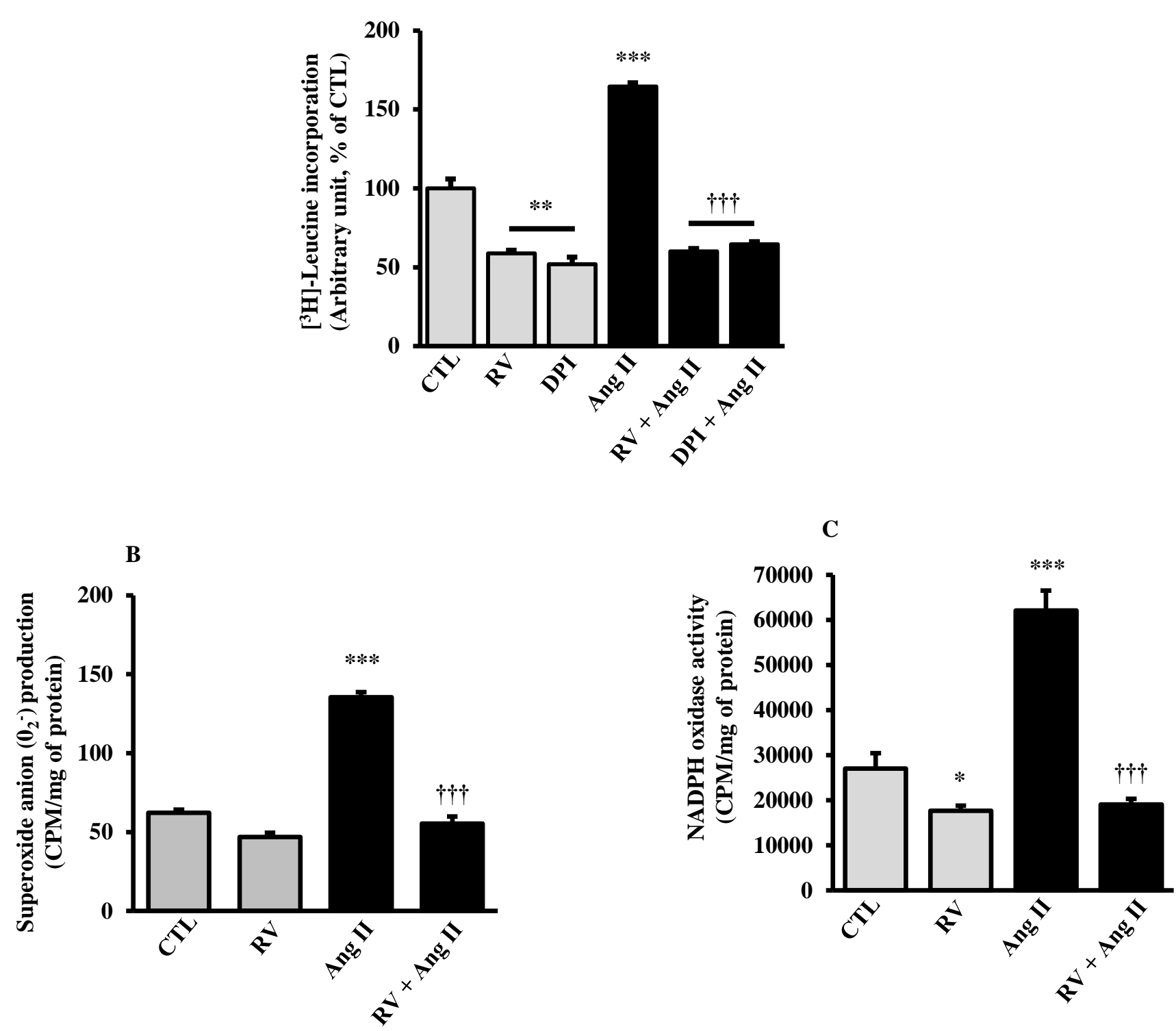

https://mc06.manuscriptcentral.com/cjpp-pubs 

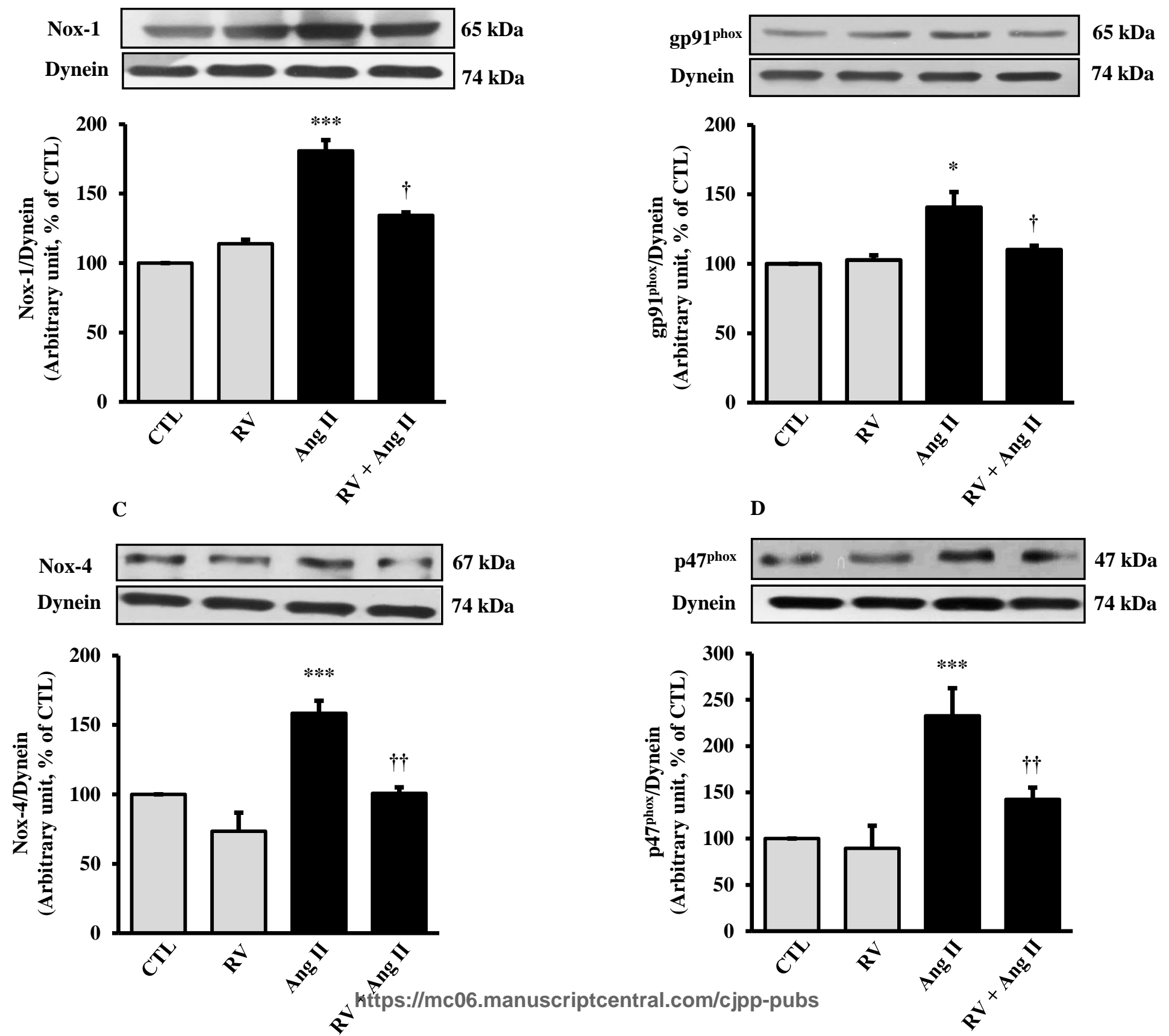
$\mathbf{A}$

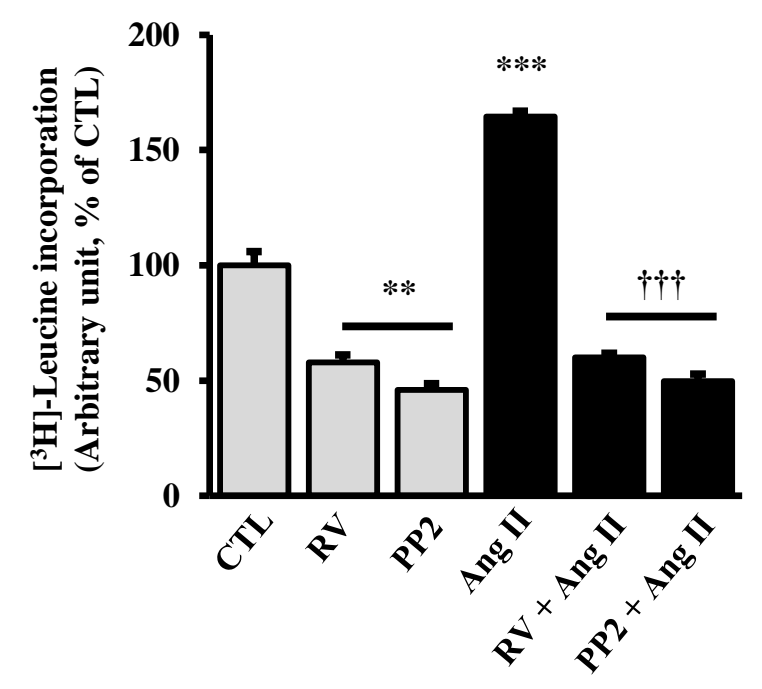

B
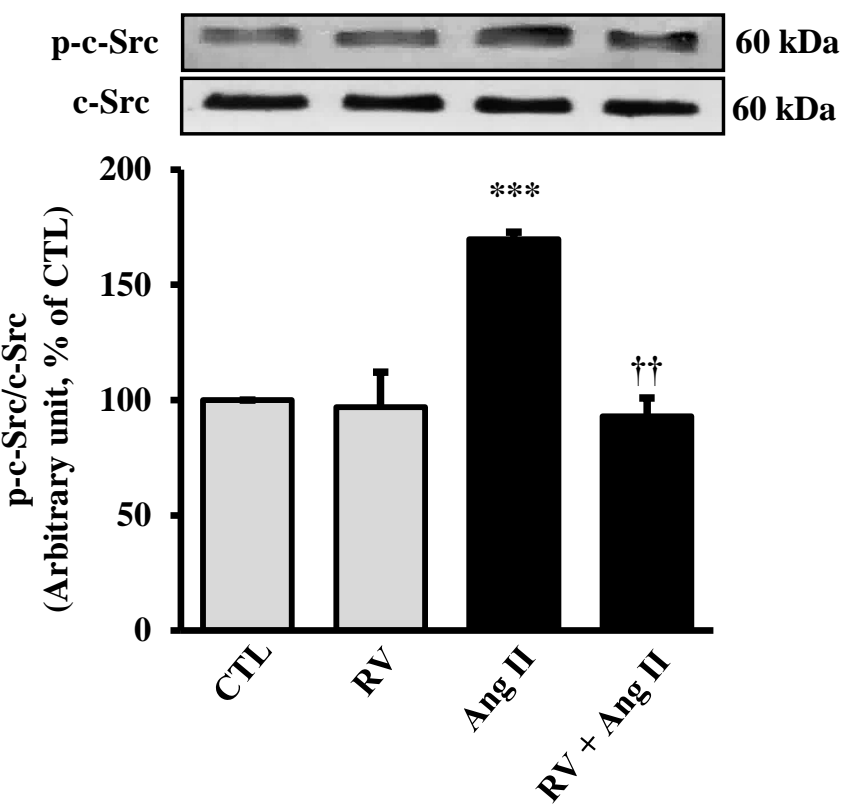
A

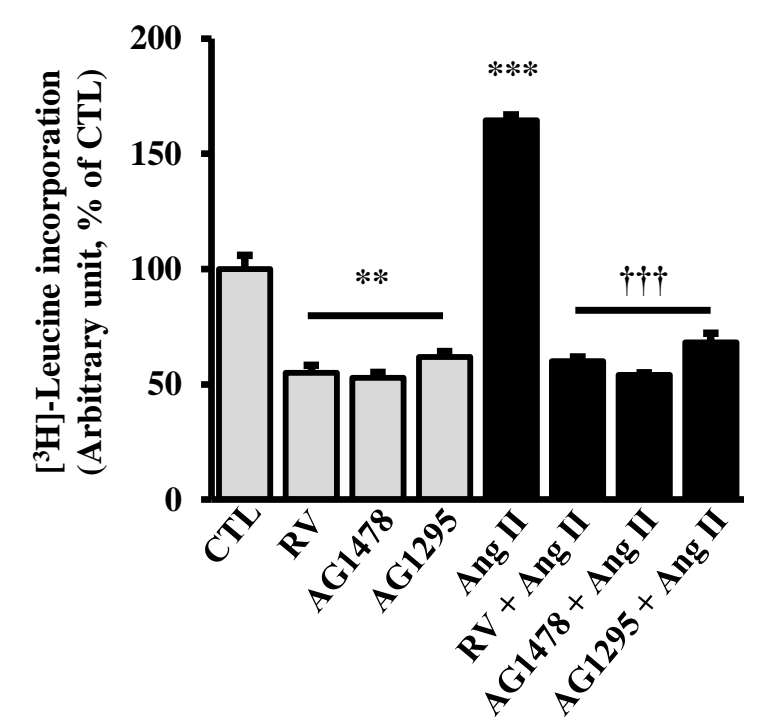

B
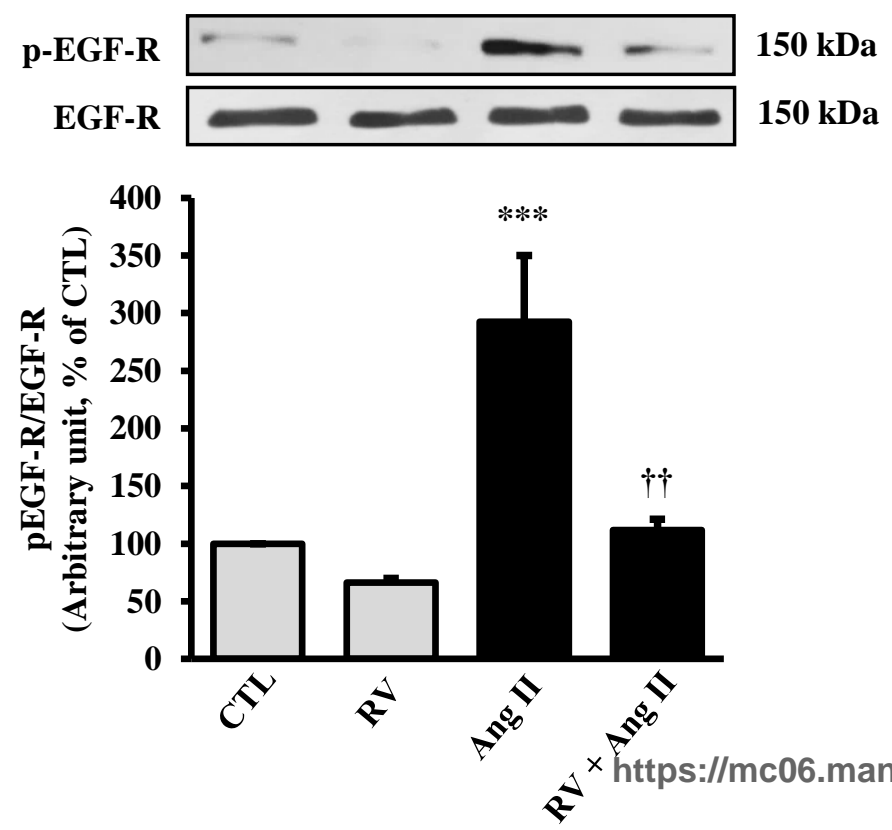

C
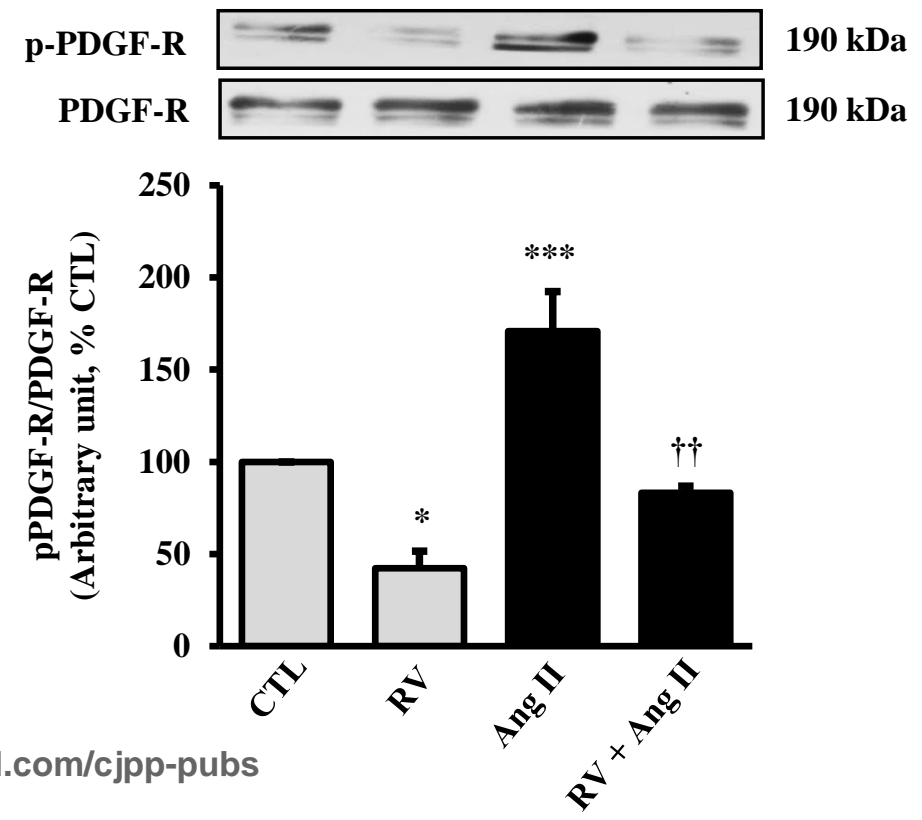

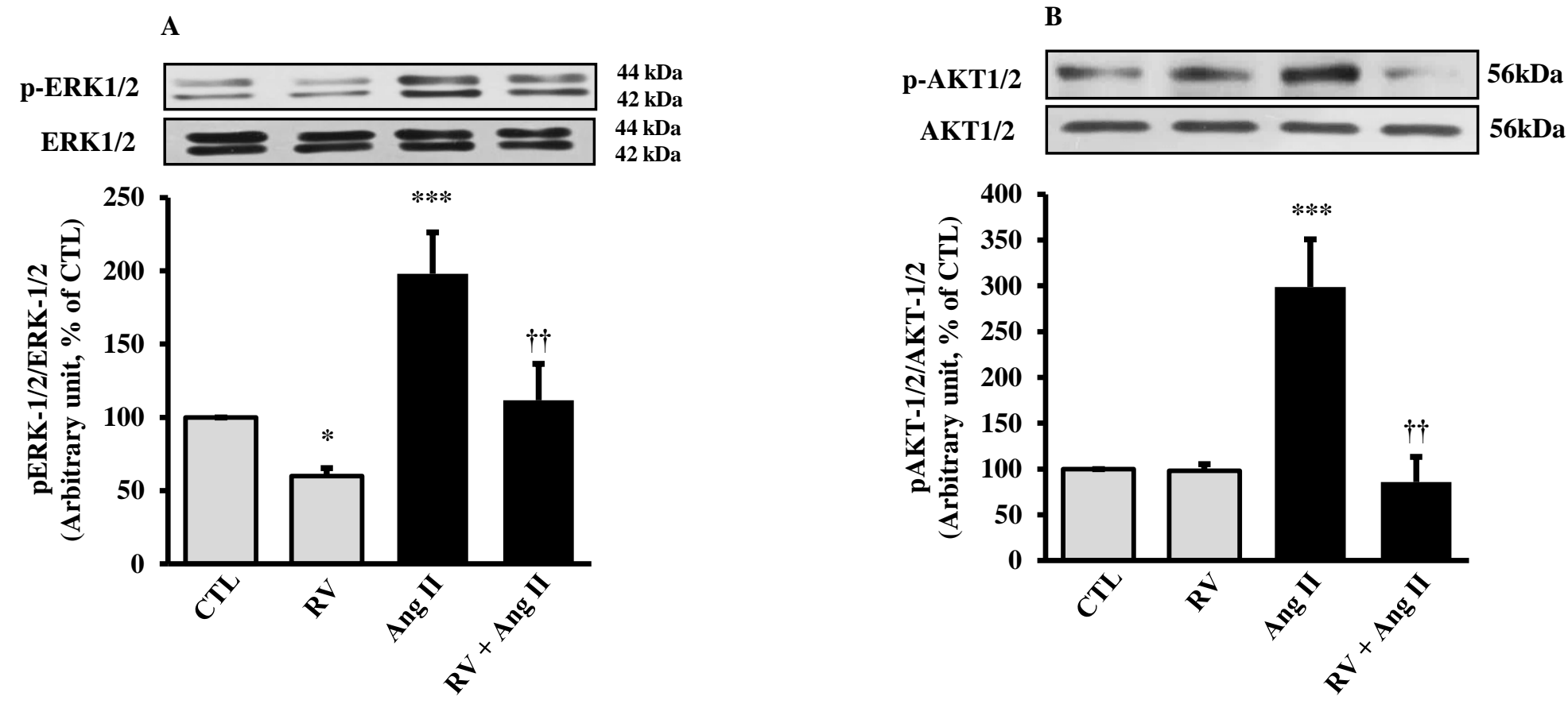